\title{
Sequence alignment analysis of proteins involved in platelet-endothelial cell interaction identifies molecular incompatibilities between Homo sapiens and Sus scrofa
}

\author{
Pengfei Chen ${ }^{1,2}$, Ying Lu ${ }^{2}$, Hanchao Gao ${ }^{2}$, Mingtao $\mathrm{Li}^{1}$, David K. C. Cooper ${ }^{3}$, Lisha Mou*1,2 \\ ${ }^{1}$ Department of Pharmacology, Zhongshan School of Medicine, Sun Yat-sen University, Guangzhou, China \\ ${ }^{2}$ Shenzhen Xenotransplantation Medical Engineering Research and Development Center, Institute of Translational Medicine; \\ Shenzhen Second People's Hospital, First Affiliated Hospital of Shenzhen University, Shenzhen, Guangdong, China \\ ${ }^{3}$ Xenotransplantation Program/Department of Surgery, The University of Alabama at Birmingham, Birmingham, AL, USA
}

Received: November 15, 2016

Accepted: February 16, 2017

Online Published: February 28, 2017

DOI: $10.5430 /$ jbei.v3n1p51

URL: https://doi.org/10.5430/jbei.v3n1p51

\begin{abstract}
Background: Platelets play a vital role in acute humoral xenograft rejection (AHXR), presenting as microvascular thrombosis in the graft and/or consumptive coagulopathy in the recipient. Adhesion and aggregation of primate platelets to the activated vascular endothelial cells through sequential binding of ligands on endothelial cells and subendothelial matrix ultimately trigger a complex biological process of prothrombotic signaling cascades. Increasing evidence suggests that the molecular incompatibilities in effector molecules across species may partially contribute to dysregulated microvascular thrombosis in xenografts.

Method: We selected amino acid sequence of candidate proteins from the NCBI database with keywords: platelet-endothelium interaction, platelet adhension, platelet aggregation, and subendothelial matrix ligands. Pair-wise amino acid alignments were made using the Emboss Needle method. Emboss needle created optimal global alignment of the amino acid sequences of human genes and pig genes using ClustalW2.

Results: Most of the proteins involved in platelet-EC interaction in Homo sapiens share high sequence similarity with their homologues in Sus scrofa. Cytokines that potentially induce endothelial damage (such as CD40L, TNF- $\alpha$ ) were highly conserved between Homo sapiens and Sus scrofa. Some endothelium-derived cytokines (such as IL-8, CCL2, CCL5) that can induce platelet activation or enhance aggregation share high sequence similarity between Homo sapiens and Sus scrofa. Some regulators that potentially transduce inhibitory signaling to control platelet activation or complement activation have relatively poor sequence identity between Homo sapiens and Sus scrofa, and some even lack their homologues in Sus scrofa.

Conclusion: These characteristics of sequence similarity of proteins involved in platelet-EC interaction indicate the molecular incompatibilities between humans and pigs. This study provides clues for explanation of excessive platelet activity in pig-toprimate xenotransplantation model.
\end{abstract}

Key Words: Endothelial cells, Molecular incompatibility, Platelets, Sequence alignment analysis, Pig-to-primate xenotransplantation

\footnotetext{
*Correspondence: Lisha Mou; Email: molly_molly@ 163.com; Address: Department of Pharmacology, Zhongshan School of Medicine, Sun Yat-sen University, 74 Zhongshan 2nd Road, Guangzhou 510080, China. 


\section{INTRODUCTION}

Acute humoral xenograft rejection (AHXR, also known as acute vascular rejection) now poses a major hurdle to long-term xenograft survival when hyperacute rejection is overcome by using multitransgenic pigs on an $\alpha 1$,3-galactosyltransferase gene-knockout (GT-KO) background. $^{[1-7]}$ AHXR is a complex, multifactorial and muticellular scenario, which is generally linked to the action of anti-donor antibodies, ${ }^{[8-12]}$ complement, ${ }^{[13-15]}$ and recipient immune components, such as platelets, ${ }^{[16-19]} \mathrm{T}$ cells, ${ }^{[20]}$ natural killer (NK) cells, ${ }^{[21,22]}$ macrophages, ${ }^{[23,24]}$ and neutrophils. ${ }^{[4,25]}$ This biological process is mainly characterized by the development of thrombotic microangiopathy, with endothelial cell (EC) swelling, apoptosis, and necrosis. ${ }^{[26]}$ It is becoming clear that AHXR results in functional impairment of a xenograft, and is inhibiting progress towards the clinical application of organ xenotransplantation.

Platelets, primarily recognized for their role in hemostasis and thrombosis, have been increasingly recognized as important mediators of AHXR, especially in the pathogenesis of microangiopathy. ${ }^{[27,28]}$ In pig-to-primate xenotransplantation, circulating primate platelets are frequently recruited to the activated vascular ECs, mainly following the deposition of natural and/or elicited anti-donor antibodies on the EC surface. ${ }^{[29]}$ A multi-step process that involves the adhesion of specific platelet-EC surface receptors with endothelial and subendothelial matrix proteins (such as collagens and von Willebrand factor), spreading of adherent platelets over the exposed subendothelial surface, and platelet aggregation, initiates the activation and procoagulant function of platelets. ${ }^{[30,31]}$ The activated platelet plugs provide the surface for the assembly of coagulation factors, and support thrombin generation. ${ }^{[32-34]}$ Excessive activation of platelets and coagulation cascades trigger the formation of plateletrich microthrombi and the development of thrombotic microangiopathy. ${ }^{[35]}$

Xenogeneic molecular incompatibilities, i.e., protein-protein interactions between donor organs and recipients (such as receptor/ligand pair), may damage normal signaling transduction. Molecular incompatibilities between pigs and primates are currently perceived as the most problematic factors in the case of pig-to-primate xenotransplantation especially in the coagulation cascade. ${ }^{[36,37]}$

One well-demonstrated evidence of molecular incompatibility involves thrombomodulin. Although porcine thrombomodulin is able to recognize and bind human thrombin, the resulting complex is a weak activator of both human protein $\mathrm{C}$ and thrombin-activatable fibrinolysis Inhibitor. ${ }^{[38]} \mathrm{In}$ contrast, porcine von Willebrand factor has been reported to be a strong agonist for human platelet GPIb receptors, resulting in robust human platelet activation. ${ }^{[39]}$ In order to control the biological effects of these incompatibilities, the generation of genetically-modified pigs has been suggested as an additional strategy to prolong xenograft survival. ${ }^{[40-42]}$

Although there has been increasing awareness of the contribution of molecular incompatibilities to xenograft failure, systematic analysis of molecular incompatibilities in the pigto-primate context has not yet been declared. In addition, molecular incompatibilities of some proteins such as TFPI or h-DAF are still controversial. ${ }^{[43-45]}$ In the present study, we systematically analyzed the amino acid sequence of proteins involved in platelet-EC interaction between humans (Homo sapiens) and pigs (Sus scrofa) by sequence alignment, aiming to explore the potential target proteins responsible for dysregulated platelet activity.

\section{MATERIALS AND METHODS}

\subsection{Data set selection}

Initially, a set of candidate proteins and their amino acid sequences (available in GenBank) was retrieved and examined. We selected candidate human protein sequence from NCBI database (http://www.ncbi.nlm.nih.gov/ 10 july 2016) with keywords: platelet-endothelium interaction, platelet adhension, platelet aggregation, and subendothelial matrix ligands. If a protein encoded by a gene has isoform(s), the isoform with maximum sequence was representative of the gene. Sequence of proteins in this study can be found in supplements.

\subsection{Alignment}

We made pair-wise amino acid alignments using the Emboss Needle method (European Molecular Biology Laboratory, ftp://emboss.open-bio.org/pub/EMBOSS/). Emboss needle created optimal global alignment of the amino acid sequences of human proteins and pig proteins using ClustalW2. The following parameters were used to obtain suitable alignment results: Matrix: BLOSUM62, GAP OPEN: 10, GAP EXTENDED: 0.5, OUTPUT FORMAT: pair, END GAP PENALTY: false, OPEN GAP OPEN: 10 and END GAP EXTEND: 0.5. The BLAST program with options "-task blastp-short" was used to search for similarities of amino acid sequence of functional domain in human proteins against the porcine protein sequence. From the BLAST results, a description associated with each BLAST alignment was parsed to find the origin of the corresponding homologous protein sequence. 


\section{RESULTS}

Sequence alignment analysis of platelet receptors involved in platelet-EC interaction

Platelet-EC interaction is the first step in the biological process of platelet activation in pig-to-primate xenotransplantation. To identify the molecular incompatibilities associated with platelet-EC interaction between Homo sapiens and Sus scrofa species, we retrieved amino acid sequence of proteins that are potentially involved in platelet-EC interaction from the United States National Center for Biotechnology Information (NCBI) database using keywords: platelet-endothelium interaction, platelet adhesion, platelet aggregation, and subendothelial matrix ligands. If a protein encoded by a gene has isoforms, we took the isoform with maximum sequence length as being representative of the gene. After data set selection, the full sequence or functional domain sequence of each proteins from Homo sapiens and Sus scrofa species were subjected to pair-wise amino acid alignments (see Figure 1).

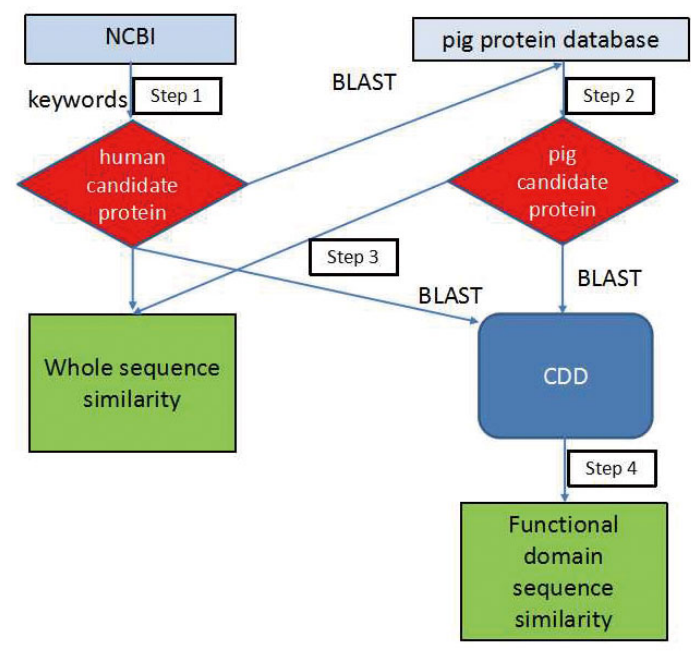

NCBI: National Center for Biotechnology Information $\mathrm{CDD}$ : NCBI's conserved domain database

Figure 1. A flow chart of the full analysis algorithm Step 1: Select candidate human protein sequence from NCBI database with keywords. Step 2: From the BLAST results, a description associated with each BLAST alignment was parsed to find the origin of the corresponding homologous protein sequence. Step 3: Make pair-wise amino acid alignments using the Emboss Needle method Emboss. Step 4: The BLAST program with options "-task blastp-short" was used to search for similarities of amino acid sequence of functional domain in human proteins against the porcine protein sequence.

Platelet-EC interaction is mediated by the binding of receptors (presented on the membrane surface of platelets) to their ligands within the extracellular matrix of injured vas- cular ECs. The well-known receptors in this process are glycoprotein (Gp) bV/IX, GpVI, integrin $\alpha_{2} \beta_{1}$, and integrin $\alpha_{I I b} \beta_{3} \cdot{ }^{[46,47]}$ We further analyzed the sequence identity of these receptors between Homo sapiens and Sus scrofa species. Among total 78 candidate genes, 66 genes in Homo sapiens share high sequence identity (ranking from $70 \%$ to $100 \%$ identity) with their homologues in Sus scrofa (see Figure 2A). Detailed analysis of the interaction domains of these receptors (selected platelet glycoproteins) revealed more conserved sequence identity between Homo sapiens and Sus scrofa species (see Table 1 and Figure 2B).
A

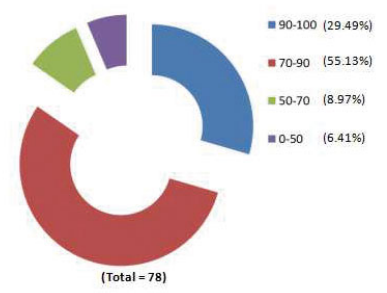

B

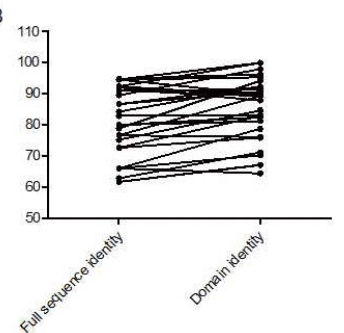

Figure 2. Sequence alignment analysis of platelet receptors involved in platelet-EC interaction (A) Frequency distributions of percent difference in full sequence alignment analysis between Homo sapiens and Sus scrofa orthologs for 78 platelet receptors. (B) Comparison of full sequence identity with domain sequence identity between Homo sapiens and Sus scrofa platelet receptors.

Sequence alignment analysis of endothelial ligands involved in platelet-EC interaction

We then analyzed the sequence identity of endothelial ligands that mediate platelet-EC interaction. Among a total 108 candidate genes, 94 genes in Homo sapiens share high sequence identity (ranking from $70 \%$ to $100 \%$ identity) with their homologues in Sus scrofa (see Figure 3A). Furthermore, sequence alignment analysis showed that nearly all the interaction domains shared $>80 \%$ sequence identity between Homo sapiens and Sus scrofa (see Table 2 and Figure 3B).

Taken together, our data demonstrated that high sequence identity exists in endothelial ligands between Homo sapiens and Sus scrofa. Thus, this characteristic of high sequence similarity probably paves the way for molecular interaction between recipient platelets and donor endothelium.

\section{Sequence alignment analysis of platelet-derived factors that contribute to EC activation}

Upon activation, platelets release a variety of proteins that can influence the metabolic, adhesive, and apoptotic properties of vascular ECs. ${ }^{[48,49]}$ Sequence alignment analysis of proteins and platelet-microparticle components released 
from platelets (a total of 169 candidate genes) identified 9 showing 90\%-100\% identity (see Figure 4). genes showing 0-50\% identity, 23 genes showing 50\%-70\% identity, 82 genes showing 70\%-90\% identity, and 55 genes

Table 1. Amino acid sequence alignment of platelet receptors between Homo sapiens and Sus scrofa

\begin{tabular}{|c|c|c|c|c|c|}
\hline Gene name & Homo sapience & Sus scrofa & Similarity(has/ssc) & Functional domain & Sequence identity \\
\hline \multirow{2}{*}{ ITGA1 } & \multirow{2}{*}{ NP_852478.1 } & \multirow{2}{*}{ XP_013840217.1 } & \multirow{2}{*}{ 83(1025/1229) } & vWFA & 96.69 \\
\hline & & & & Int_alpha & 92.31 \\
\hline \multirow{2}{*}{ ITGA2 } & \multirow{2}{*}{ NP_002194.2 } & \multirow{2}{*}{ NP_001231201.1 } & \multirow{2}{*}{$94(1109 / 1181)$} & vWFA & 92.27 \\
\hline & & & & Int_alpha & 90.74 \\
\hline \multirow{2}{*}{ ITGA2B } & \multirow{2}{*}{ NP_000410.2 } & \multirow{2}{*}{ NP_999163.1 } & \multirow{2}{*}{ 87(907/1039) } & Int_alpha & 87.27 \\
\hline & & & & Int_alpha & 94.23 \\
\hline ITGA4 & NP_000876.3 & XP_003133565.1 & 94(969/1034) & Int_alpha & 96.23 \\
\hline \multirow{2}{*}{ ITGAL } & \multirow{2}{*}{ NP_001107852.1 } & \multirow{2}{*}{ XP_005653056.1 } & \multirow{2}{*}{ 79(929/1181) } & vWFA & 75.37 \\
\hline & & & & Int_alpha & 84.62 \\
\hline \multirow{2}{*}{ ITGAM } & \multirow{2}{*}{ NP_000623.2 } & \multirow{2}{*}{ XP_003124540.4 } & \multirow{2}{*}{$88(1010 / 1152)$} & vWFA & 81.25 \\
\hline & & & & Int_alpha & 89.36 \\
\hline ITGAV & NP_001138471.1 & NP_001077401.1 & 93(973/1049) & Int_alpha & 98.18 \\
\hline \multirow{2}{*}{ ITGB1 } & \multirow{2}{*}{ NP_002202.2 } & \multirow{2}{*}{ NP_999133.1 } & \multirow{2}{*}{ 98(778/798) } & vWFA & 95.13 \\
\hline & & & & Integrin_B_tail & 89.77 \\
\hline \multirow{2}{*}{ ITGB2 } & \multirow{2}{*}{ NP_000202.3 } & \multirow{2}{*}{ NP_999073.1 } & \multirow{2}{*}{$90(691 / 769)$} & vWFA & 92.07 \\
\hline & & & & Integrin_B_tail & 57.69 \\
\hline \multirow{2}{*}{ ITGB3 } & & & & vWFA & 92.69 \\
\hline & NP_000203.2 & NP_99916\%.1 & $97(762 / 788)$ & Integrin_B_tail & 89.29 \\
\hline & & & & vWFA & 89.95 \\
\hline ITGB4 & NP_000204.3 & XP_013834/29.1 & 93(1/03/1824) & Integrin_B_tail & 86.9 \\
\hline & & & & vWFA & 93.65 \\
\hline ITGB6 & NP_0008/9.2 & NP_001090892.1 & $97(764 / 788)$ & Integrin_B_tail & 92.77 \\
\hline & & & & vWFA & 91.84 \\
\hline 11GB/ & NP_000880.1 & XP_0138411/3.1 & $92(/ 34 / 800)$ & Integrin_b_cyt & 88.1 \\
\hline & & & & LRRNT & 59.38 \\
\hline GPIBA & NP_000164.5 & XP_013836/17.1 & 67(448/665) & TPKR_C2 & 67.74 \\
\hline & & & & TPKR_C2 & 89.36 \\
\hline GPIBВ & NP_000398.1 & NP_00113545/.1 & $86(1 / 8 / 20 /)$ & LRRNT & 91.43 \\
\hline GP5 & NP 0044791 & XP 0031326491 & $82(465 / 569)$ & TPKR_C2 & 73.08 \\
\hline GPS & NP_0044/9.1 & XP_003132649.1 & $8<(465 / 569)$ & LRR_RI & 81.09 \\
\hline CPG & ND 001077368 ? & XP 0056560142 & $32(219 / 694)$ & Ig & 75.9 \\
\hline GPD & NP_UU10/7368.2 & XP_005656014.2 & $32(219 / 694)$ & Ig & 82.95 \\
\hline GP9 & NP_000165.1 & NP_001135461.1 & 75(133/178) & TPKR_C2 & 64.44 \\
\hline CD36 & NP_000063.2 & XP_013835246.1 & $94(442 / 472)$ & CD36 & 82.96 \\
\hline
\end{tabular}

From our analysis, TIMP metallopeptidase inhibitor-3, Furthermore, we also identified some proteins in our candibone morphogenetic protein-4, peptidylprolyl isomerase A, date list potentially bearing the ability to protect ECs from angiopoietin-1, crystalline- $\alpha \mathrm{B}$, insulin-like growth factor-1, activation or apoptosis (according to previous studies) (see vascular endothelial growth factor (VEGF), Notch-2, CD40L, Table 4). However, sequence alignment analysis showed and TNF- $\alpha$ bear highly-conserved sequence identity between that these proteins had relatively poor sequence identity (see Homo sapiens and Sus scrofa, indicating the possibility of overcoming molecular incompatibility between species to functionally mediate signaling that contributes to vascular EC activation and/or apoptosis in xenograft (see Table 3).

Consistent with our study, human CD40L has been demonstrated to interact with porcine CD40 and activate porcine ECs. ${ }^{[50]}$ Human TNF- $\alpha$ has also been demonstrated to induce porcine EC activation and immune-mediated microvascular injury. ${ }^{[51-53]}$

Table 4).

Taken together, most of the chemokines or ligands released from recipient platelets or other cell types that may contribute to vascular EC activation have high sequence identity between Homo sapiens and Sus scrofa. However, some potentially protective factors exhibit poor sequence identity. These characteristics of sequence similarity may contribute to persistent EC activation in xenotransplantation. 
Table 2. Amino acid sequence alignment of endothelial ligands between Homo sapiens and Sus scrofa

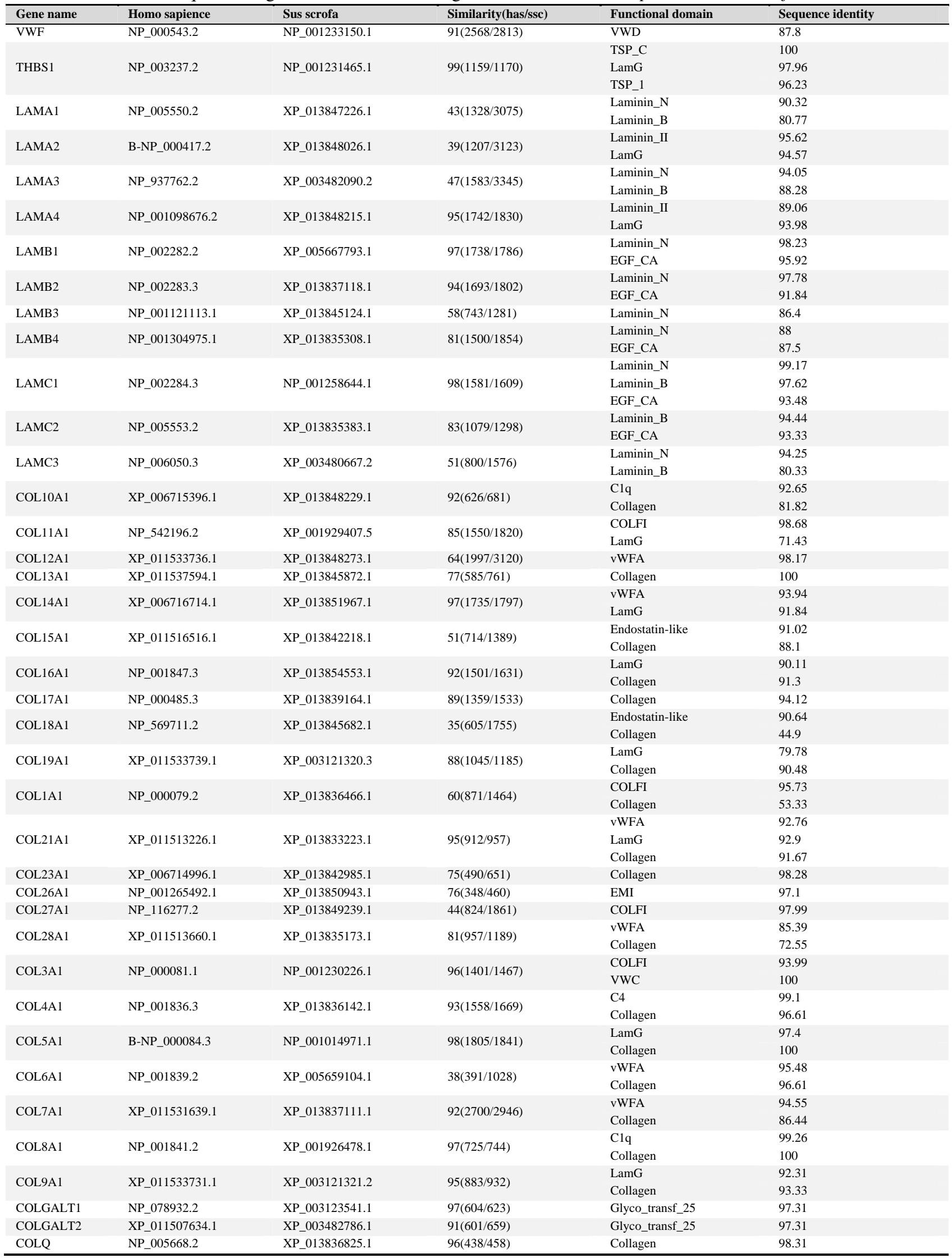



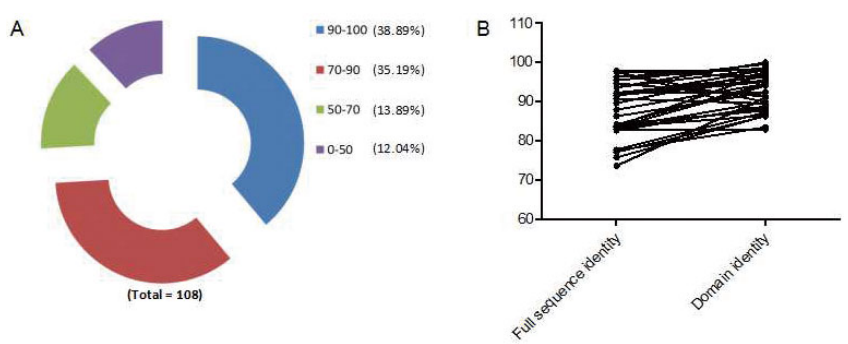

Figure 3. Sequence alignment analysis of endothelial ligands involved in platelet-EC interaction (A) Frequency distributions of percent difference in full sequence alignment analysis between Homo sapiens and Sus scrofa orthologs for 108 endothelial ligands. (B) Comparison of full sequence identity with domain sequence identity between Homo sapiens and Sus scrofa endothelial ligands.

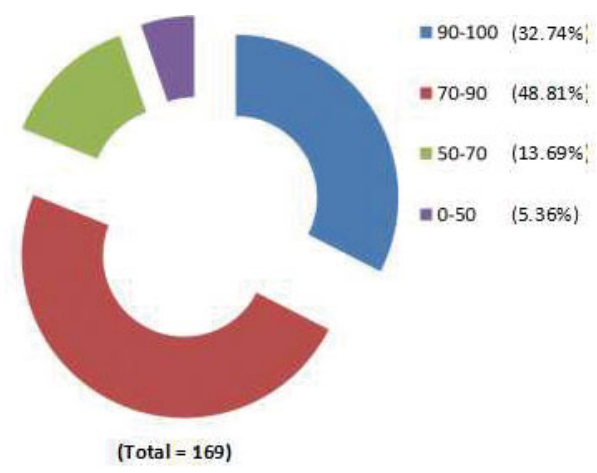

Figure 4. Sequence alignment analysis of platelet-derived factors that contribute to EC activation. Frequency distributions of percent difference in full sequence alignment analysis between Homo sapiens and Sus scrofa orthologs for 169 platelet-derived factors.

Table 3. Amino acid sequence alignment of platelet-derived factors between Homo sapiens and Sus scrofa

\begin{tabular}{|c|c|c|c|c|c|}
\hline Gene name & Homo sapience & Sus scrofa & Similarity(has/ssc) & Functional domain & $\begin{array}{l}\text { Sequence } \\
\text { identity }\end{array}$ \\
\hline TIMP1 & NP_003245.1 & NP_999022.1 & 91(188/207) & NTR_like & 84.66 \\
\hline TIMP2 & NP_003246.1 & NP_001139457.1 & $99(218 / 221)$ & NTR_like & 98.36 \\
\hline TIMP3 & NP_000353.1 & XP_003126121.3 & $100(211 / 211)$ & NTR_like & 100 \\
\hline BMP4 & NP_001193.2 & XP_005660027.1 & $99(404 / 409)$ & TGFb_propeptide & 97.46 \\
\hline BMP7 & NP_001710.1 & XP_005673101.1 & $99(425 / 431)$ & TGFb_propeptide & 97.98 \\
\hline PPIA & NP_001287910.1 & XP_013841254.1 & $99(104 / 105)$ & cyclophilin & 99.02 \\
\hline ANGPT1 & NP_001137.2 & NP_999124.1 & $99(493 / 498)$ & FReD & 98.15 \\
\hline CRYAB & NP_001276736.1 & XP_005667377.1 & $98(171 / 175)$ & alpha-crystallin-Hsps_p23-like & 98.81 \\
\hline IGF1 & NP_000609.1 & XP_005664255.1 & $97(149 / 153)$ & IlGF_like & 100 \\
\hline NOTCH2 & NP_001186930.1 & XP_013852682.1 & $49(1199 / 2471)$ & EGF_CA & 89.19 \\
\hline CD40LG & NP_000065.1 & NP_999291.1 & $91(237 / 261)$ & TNF & 88.71 \\
\hline CCL5 & NP_001265665.1 & XP_013845402.1 & $43(68 / 158)$ & Chemokine & 74.19 \\
\hline SELP & NP_002996.2 & NP_999243.1 & $66(550 / 830)$ & CLECT & 76.47 \\
\hline VEGFA & NP_001020537.2 & XP_013833429.1 & $64(299 / 471)$ & PDGF & 97.59 \\
\hline WNT5A & NP_001243034.1 & XP_013837252.1 & $95(362 / 380)$ & wnt & 100 \\
\hline IL1A & NP_000566.3 & XP_013843310.1 & $83(226 / 272)$ & IL1 & 64.29 \\
\hline IL1B & NP_000567.1 & NP_999220.1 & $75(203 / 270)$ & IL1 & 68.03 \\
\hline IFNB1 & NP_002167.1 & NP_001003923.1 & $81(151 / 187)$ & IFab & 61.22 \\
\hline IFNG & NP_000610.2 & NP_999113.1 & $75(124 / 166)$ & IFN-gamma & 59.4 \\
\hline HBEGF & NP_001936.1 & NP_999464.1 & $93(194 / 208)$ & PHA02887 & 100 \\
\hline HIF1A & NP_001230013.1 & NP_001116596.1 & $93(790 / 851)$ & $\begin{array}{l}\text { PAS } \\
\text { HIF-1a_CTAD }\end{array}$ & $\begin{array}{l}100 \\
100\end{array}$ \\
\hline TNF & NP_000585.2 & NP_999187.1 & $92(215 / 233)$ & TNF & 90.15 \\
\hline IL17A & NP_002181.1 & NP_001005729.1 & $84(130 / 155)$ & IL17 & 82.28 \\
\hline IL17B & NP_055258.1 & XP_013850776.1 & $75(171 / 228)$ & IL17 & 97.62 \\
\hline IL17D & NP_612141.1 & XP_013834169.1 & $77(166 / 215)$ & IL17 & 82.93 \\
\hline CXCL4 & NP_001502.1 & XP_005666809.1 & 74.77 & Chemokine & 80.95 \\
\hline CXCL1 & NP_002610.1 & NP_999041.1 & 45.87 & Chemokine & 72 \\
\hline
\end{tabular}


Table 4. Amino acid sequence alignment of candidates potentially bearing the function to protect endothelial cells between Homo sapiens and Sus scrofa

\begin{tabular}{llllll}
\hline Gene name & Homo sapience & Sus scrofa & Similarity(has/ssc) & Functional domain & Sequence identity \\
\hline \multirow{2}{*}{ CD74 } & NP_001020330.1 & NP_998939.1 & 65.2(193/296) & MHCassoc_trimer & 68.66 \\
\multirow{2}{*}{ IL-R antagonist } & NP_776213.1 & NP_999427.1 & $73.4(141 / 192)$ & IL1 & 35.71 \\
CCL26 & NP_006063.1 & NP_001009579.1 & 41.11 & Chemokine & 38.46 \\
Urocortin & NP_003344.1 & XP_005663105.1 & 48 & CRF & 47.37 \\
\hline
\end{tabular}

\section{Sequence alignment analysis of endothelium-derived regulators that affect platelet activation}

Besides activation by primary agonists, platelets can also be activated by chemokines produced by ECs. Analysis of endothelium-derived regulators (a total of 53 candidate proteins) indicated that most of these proteins $(80 \%)$ in Homo sapiens have more than $70 \%$ sequence identity with their homologues in Sus scrofa (see Figure 5). EC-derived CCL2 (monocyte chemotactic protein-1, MCP-1), CXCL8 (interleukin 8, IL-8), CXCL12, CX3CL1 and CCL5 have been reported as strong activators of platelets and can promote platelet aggregation. ${ }^{[54-56]}$ Analysis of these chemokines and other potential candidates showed that most of these proteins share high sequence identity between Homo sapiens and Sus scrofa (see Table 5).

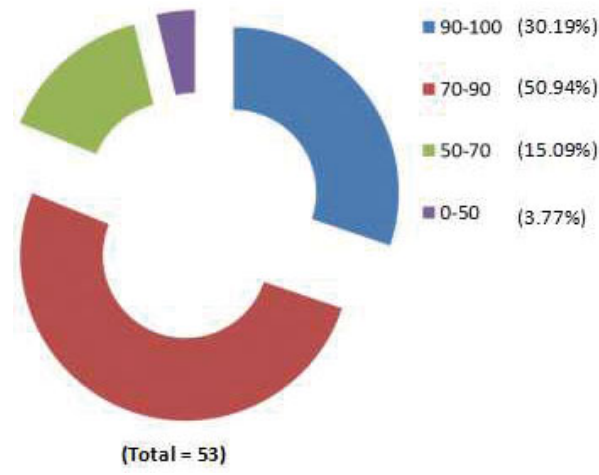

Figure 5. Sequence alignment analysis of endothelium-derived regulators that affect platelet activation. Frequency distributions of percent difference in full sequence alignment analysis between Homo sapiens and Sus scrofa orthologs for 53 endothelium-derived regulators.

Table 5. Amino acid sequence alignment of endothelium-derived regulators between Homo sapiens and Sus scrofa

\begin{tabular}{llllll}
\hline Gene name & Homo sapience & Sus scrofa & Similarity(has/ssc) & Functional domain & Sequence identity \\
\hline CCL2 & NP_002973.1 & NP_999379.1 & 88(87/99) & Chemokine & 79.31 \\
CCL4 & NP_002975.1 & NP_998944.1 & $95(87 / 92)$ & Chemokine & 80.7 \\
CCL5 & NP_001265665.1 & XP_013845402.1 & 43(68/158) & Chemokine & 74.19 \\
CX3CL1 & NP_002987.1 & XP_013843976.1 & 72(292/408) & Chemokine & 55.84 \\
CXCL12 & NP_001171605.1 & NP_001009580.1 & $61(92 / 150)$ & Chemokine & 96.77 \\
IL-8 & NP_000575.1 & XP_003362006.1 & 82(84/103) & Chemokine & 79.69 \\
LEP & NP_000221.1 & NP_999005.1 & $92(153 / 167)$ & Leptin & 87.32 \\
LGALS1 & NP_002296.1 & NP_001001867.1 & $92(124 / 135)$ & GLECT & 85.48 \\
LGALS3 & NP_001170859.1 & XP_013848886.1 & $67(173 / 260)$ & GLECT & 89.47 \\
\hline
\end{tabular}

Endothelium-derived regulators can also transduce inhibitory signaling to control platelet activation, and these include immunoreceptor tyrosine-based inhibitory motif (ITIM)-containing receptors, cell surface receptors, or small molecules. Sequence alignment analysis showed that these molecules have relatively less sequence identity between Homo sapiens and Sus scrofa, and some even lack their homologues in Sus scrofa (see Table 6). 
Table 6. Amino acid sequence alignment of endothelium-derived inhibitory regulators between Homo sapiens and Sus scrofa

\begin{tabular}{llllll}
\hline Gene name & Homo sapience & Sus scrofa & Similarity(has/ssc) & Functional domain & Sequence identity \\
\hline CD46 & NP_758869.1 & NP_999053.1 & $54(229 / 421)$ & CCP & 46.67 \\
CD55 & NP_000565.1 & NP_998980.1 & $48(239 / 502)$ & CCP & 33.33 \\
CEACAM1 & NP_001703.2 & XP_005655946.2 & $61(323 / 527)$ & Ig & 61.9 \\
ESAM & NP_620411.2 & XP_005667518.1 & $86(337 / 394)$ & Ig & 74.34 \\
F11R & NP_058642.1 & NP_001121916.1 & $88(264 / 299)$ & Ig & 77.78 \\
PECAM1 & NP_000433.4 & NP_999072.1 & $84(620 / 740)$ & Ig & 66.67 \\
SERPINE1 & NP_000593.1 & NP_999075.1 & $93(373 / 402)$ & SERPIN & 88.33 \\
VIPR1 & NP_004615.2 & XP_005669452.1 & $92(420 / 459)$ & 7 tm_4 & 89.43 \\
urocortin-2 & NP_149976.1 & XP_013837113.1 & $73.5(83 / 113)$ & - & \\
CD74 & NP_001020330.1 & NP_998939.1 & $65.2(193 / 296)$ & MHCassoc_trimer & 68.66 \\
IL-R antagonist & NP_776213.1 & NP_999427.1 & $73.4(141 / 192)$ & TY & 35.71 \\
TNFRSF 10C & NP_003832.2 & - & & & 38.46 \\
TNFRSF 10D & NP_003831.2 & - & & & \\
G6b-B & NP_612116.1 & - & & & \\
\hline
\end{tabular}

Taken together, these data indicate that most of the endothelium derived chemokines share high sequence identity between Homo sapiens and Sus scrofa, while some of the inhibitory regulators have relatively poor sequence identity. These characteristic of sequence identity may facilitate platelet activation by endothelium-derived regulators.

\section{Discussion}

Uncontrolled activation of platelets and coagulation cascades trigger the formation of platelet-rich microthrombi and the development of thrombotic microangiopathy that is a major cause of xenograft failure. However, the study of molecular incompatibilities with regard to platelet activity in pig-toprimate xenotransplantation has been limited. In our analysis, (1) most of the proteins involved in platelet-EC interaction in Homo sapiens share high sequence similarity with their homologues in Sus scrofa; (2) nearly all the endothelial ligands, including collagen, laminin, von Willebrand factor, and thrombin, share high sequence similarity between Homo sapiens and Sus scrofa; (3) cytokines that potentially induce endothelial damage (such as CD40L, TNF- $\alpha$ ) were highly conserved between Homo sapiens and Sus scrofa; (4) some endothelium-derived cytokines (such as IL-8, CCL2, CCL5) that can induce platelet activation or enhance aggregation share high sequence similarity between Homo sapiens and Sus scrofa; (5) regulators that potentially transduce inhibitory signaling to control platelet activation or complement activation have relatively poor sequence identity between Homo sapiens and Sus scrofa, and some even lack their homologues in Sus scrofa.

Sequence alignment analysis can be used to screen molecular incompatibilities of proteins between species. For example, porcine thrombomodulin has about $78 \%$ sequence similarity with human thrombomodulin, and porcine thrombomodulin is able to recognize and bind human thrombin, but the resulting complex is a weak activator of both human protein $\mathrm{C}$ and thrombin-activatable fibrinolysis Inhibitor. ${ }^{[38]}$ Thus, from our analysis, the function of candidate targets needs to be confirmed experimentally. Furthermore, it is worthy of note that the availability, annotation, integrity of the Sus scrofa genome provide some obstacles that may ultimately affect the accuracy and integrity of our results.

It is reasonable for some regulators to have compatible functions across species, but abnormal expression may contribute to incompatible phenotypes. For example, coagulation is exacerbated during inflammation by the down-regulation and degradation of critical endothelial anticoagulant and antiplatelet systems. This is best illustrated by the influence of inflammatory TNF- $\alpha$ and IFN- $\gamma$ on thrombomodulin gene expression and mRNA stability, ${ }^{[57-59]}$ as well as proteolytic inactivation of endothelial protein $\mathrm{C}$ receptor (EPCR) by neutrophil proteinase-3..$^{60]}$

Our data provide a basic perspective for understanding molecular incompatibilities that may relate to excessive platelet activity in pig-to-primate xenotransplantation, and also provide a clue for strategies to control excessive platelet function in prevention of thrombosis. The high sequence similarity as we observed in proteins involved in platelet-EC interaction, endothelial ligands and endothelium-derived cytokines thus provide explanations to excessive platelet activation in pigto-primate xenotransplantation. To prevent platelet activation and thrombus formation, blockade of signaling transduction 
between donor endothelium and recipient platelet by targeting these candidates may be an efficient strategy. Actually, inhibition of platelet integrin GPIIbIIIa was demonstrated to reduce intravascular thrombosis and prolong survival of discordant cardiac xenografts. ${ }^{[61,62]}$ Alternatively, genetic knock out of von Willebrand factor prolonged survival of porcine pulmonary xenografts. ${ }^{[63]}$

It was especially interesting that we identified several regulators that potentially transduce inhibitory signaling to control platelet activation or complement activation from previous report. However, these regulators have relatively poor sequence identity between Homo sapiens and Sus scrofa, and some even lack their homologues in Sus scrofa. The next step will be to experimentally verify their inhibitory potential in xenotransplantation model.

Fundings: This work was supported by grants from the National Natural Science Foundation of China (Grant No.
81501385), Shenzhen Municipal Commission of Science and Technology (Grant No. JCYJ20150330102720149), Shenzhen Foundation of Science and Technology (Grant No. JCYJ20160229204849975 and GCZX2015043017281705), Fund for High Level University's Medical Discipline Construction (Grant No. 2016031638) and Sanming Project of Medicine in Shenzhen (2014).

Author Contributions: Pengfei Chen, Ying Lu and Hanchao Gao contributed equally to this work. Pengfei Chen and Ying Lu formed the original idea. Pengfei Chen, Ying Lu and Hanchao Gao analyzed the data. Pengfei Chen wrote the initial manuscript. David K. C. Cooper revised the manuscript. Lisha Mou supervised the study. All authors read and approved the final manuscript.

\section{CONFLiCTS OF INTEREST Disclosure}

The authors have no financial conflicts of interest.

\section{REFERENCES}

[1] Yamada K, Yazawa K, Shimizu A, et al. Marked prolongation of porcine renal xenograft survival in baboons through the use of alpha1,3-galactosyltransferase gene-knockout donors and the cotransplantation of vascularized thymic tissue. Nature Medicine. 2005; 11 : 32-4. PMid:15619627. https://doi.org/10.1038/nm1172

[2] Kuwaki K, Tseng YL, Dor FJ, et al. Heart transplantation in baboons using alpha1,3-galactosyltransferase gene-knockout pigs as donors: initial experience. Nature Medicine. 2005; 11: 29-31. PMid:15619628. https://doi .org/10.1038/nm1171

[3] Shimizu A, Hisashi Y, Kuwaki K, et al. Thrombotic microangiopathy associated with humoral rejection of cardiac xenografts from alpha1,3-galactosyltransferase gene-knockout pigs in baboons. The American Journal of Pathology. 2008; 172: 1471-81. PMid:18467706. https://doi.org/10.2353/ajpath.2008.070672

[4] Ezzelarab M, Garcia B, Azimzadeh A, et al. The innate immune response and activation of coagulation in alpha1,3galactosyltransferase gene-knockout xenograft recipients. Transplantation. 2009; 87: 805-12. PMid:19300181. https://doi .org/10 $.1097 /$ TP. 0b013e318199c34f

[5] Cooper DK, Satyananda V, Ekser B, et al. Progress in pig-to-nonhuman primate transplantation models (1998-2013): a comprehensive review of the literature. Xenotransplantation. 2014; 21: 397-419. PMid:25176336. https://doi.org/10.1111/xen.12127

[6] Mohiuddin MM, Singh AK, Corcoran PC, et al. One-year heterotopic cardiac xenograft survival in a pig to baboon model. American Journal of Transplantation: official journal of the American Society of Transplantation and the American Society of Transplant Surgeons. 2014; 14: 488-9. PMid:24330419. https://doi.org/10.1111/ ajt. 12562

[7] Michel SG, Madariaga ML, Villani V, et al. Current progress in xenotransplantation and organ bioengineering. International Journal of Surgery. 2015; 13: 239-44. PMid:25496853. https://doi.org/ $10.1016 / j . i j s u .2014 .12 .011$

Published by Sciedu Press
[8] Lin SS, Weidner BC, Byrne GW, et al. The role of antibodies in acute vascular rejection of pig-to-baboon cardiac transplants. The Journal of Clinical Investigation. 1998; 101: 1745-56. PMid:9541506. https://doi.org/10.1172/JCI2134

[9] Trpkov K, Campbell P, Pazderka F, et al. Pathologic features of acute renal allograft rejection associated with donor-specific antibody, Analysis using the Banff grading schema. Transplantation. 1996; 61: 1586-92. PMid:8669102. https://doi.org/10.1097/ 00007890-199606150-00007

[10] Cascalho M, Platt JL. The immunological barrier to xenotransplantation. Immunity. 2001; 14: 437-46. https://doi.org/10.1016/ S1074-7613(01) 00124-8

[11] Chen RH, Kadner A, Adams DH. Monitoring pig-to-primate cardiac xenografts with live Internet images of recipients and xenograft telemetric signals: histologic and immunohistochemical correlations. The Journal of Heart and Lung Transplantation: the official publication of the International Society for Heart Transplantation. 2000; 19: 591-7. https://doi.org/10.1016/S1053-2498(00)00101-7

[12] Hisashi Y, Yamada K, Kuwaki K, et al. Rejection of cardiac xenografts transplanted from alpha1,3-galactosyltransferase geneknockout (GalT-KO) pigs to baboons. American Journal of Transplantation: official journal of the American Society of Transplantation and the American Society of Transplant Surgeons. 2008; 8: 2516-26. PMid:19032222. https://doi.org/10.1111/j.1600 $-6143.2008 .02444 . \mathrm{x}$

[13] Bengtsson A, Svalander CT, Molne J, et al. Extracorporeal ("ex vivo") connection of pig kidneys to humans. III. Studies of plasma complement activation and complement deposition in the kidney tissue. Xenotransplantation. 1998; 5: 176-83. https://doi.org/10.111 $1 / j .1399-3089.1998 . t b 00025 . x$

[14] Tector AJ, Chen X, Soderland C, et al. Complement activation in discordant hepatic xenotransplantation. Xenotransplantation. 1998; 5: 257-61. https://doi.org/10.1111/j.1399-3089.1998.t b00036. $x$ 
[15] Loss M, Vangerow B, Schmidtko J, et al. Acute vascular rejection is associated with systemic complement activation in a pig-to-primate kidney xenograft model. Xenotransplantation. 2000; 7: 186-96. https://doi.org/10.1034/j.1399-3089.2000.00059.x

[16] Breimer ME, Bjorck S, Svalander CT, et al. Extracorporeal ("ex vivo") connection of pig kidneys to humans. I. Clinical data and studies of platelet destruction. Xenotransplantation. 1996; 3: 328-39.

[17] Schulte am Esch J, Cruz MA, Siegel JB, et al. Activation of human platelets by the membrane-expressed A1 domain of von Willebrand factor. Blood. 1997; 90: 4425-37.

[18] Robson SC, Cooper DK, d'Apice AJ. Disordered regulation of coagulation and platelet activation in xenotransplantation. Xenotransplantation. 2000; 7: 166-76. https://doi.org/10.1034/j.1399-3 $089.2000 .00067 . \mathrm{x}$

[19] Lin CC, Chen D, McVey JH, et al. Expression of tissue factor and initiation of clotting by human platelets and monocytes after incubation with porcine endothelial cells. Transplantation. 2008; 86: 702-9. PMid:18791452. https ://doi.org/10.1097/TP.0b013e31818 $410 \mathrm{a} 3$

[20] Davila E, Byrne GW, LaBreche PT, et al. T-cell responses during pig-to-primate xenotransplantation. Xenotransplantation, 2006; 13 31-40. PMid:16497210. https://doi.org/10.1111/j.1399-3 $089.2005 .00258 . \mathrm{x}$

[21] Candinas D, Belliveau S, Koyamada N, et al. T cell independence of macrophage and natural killer cell infiltration, cytokine production, and endothelial activation during delayed xenograft rejection. Transplantation, 1996; 62: 1920-7. https ://doi.org/10.1097/0000 7890-199612270-00042

[22] Itescu S, Kwiatkowski P, Artrip JH, et al. Role of natural killer cells, macrophages, and accessory molecule interactions in the rejection of pig-to-primate xenografts beyond the hyperacute period. Human Immunology. 1998; 59: 275-86. https ://doi.org/10.1016/S0 198-8859 (98) 00026-3

[23] Lin Y, Vandeputte M, Waer M. Contribution of activated macrophages to the process of delayed xenograft rejection. Transplantation. 1997; 64: 1677-83. https://doi.org/10.1097/00007890-1997122 70-00008

[24] Ide K, Ohdan H, Kobayashi T, et al. Antibody- and complementindependent phagocytotic and cytolytic activities of human macrophages toward porcine cells. Xenotransplantation. 2005; 12 : 181-8. PMid:15807768. https://doi.org/10.1111/j.1399-3 $089.2005 .00222 . \mathrm{x}$

[25] Schuurman HJ, Cheng J, Lam T. Pathology of xenograft rejection: a commentary. Xenotransplantation. 2003; 10: 293-9. https: //doi.org/10.1034/j.1399-3089.2003.02092.x

[26] Shimizu A, Meehan SM, Kozlowski T, et al. Acute humoral xenograft rejection: destruction of the microvascular capillary endothelium in pig-to-nonhuman primate renal grafts. Laboratory Investigation; a journal of technical methods and pathology. 2000; 80: 815-30. https://doi.org/10.1038/labinvest. 3780086

[27] Iwase H, Ekser B, Zhou H, et al. Platelet aggregation in humans and nonhuman primates: relevance to xenotransplantation. Xenotransplantation. 2012; 19: 233-43. PMid:22909136. https ://doi.org/ $10.1111 / \mathrm{j} .1399-3089.2012 .00712 . \mathrm{x}$

[28] Iwase H, Ekser B, Hara H, et al. Regulation of human platelet aggregation by genetically modified pig endothelial cells and thrombin inhibition. Xenotransplantation. 2014; 21: 72-83. PMid:24188473. https://doi.org/10.1111/xen.12073

[29] Cozzi E, Bosio E, Seveso M, et al. Xenotransplantation-current status and future perspectives. British medical bulletin. 2005; 75-76: 99-114.
[30] Mackman N. Triggers, targets and treatments for thrombosis. Nature. 2008; 451: 914-8. PMid:18288180. https ://doi.org/10.1038/ nature 06797

[31] Furie B, Furie BC. Mechanisms of thrombus formation. The New England Journal of Medicine. 2008; 359: 938-49. PMid:18753650. https://doi.org/10.1056/NEJMra0801082

[32] Monroe DM, Hoffman M, Roberts HR. Platelets and thrombin generation. Arteriosclerosis, Thrombosis, and Vascular Biology. 2002; 22: 1381-9. https://doi.org/10.1161/01. ATV.0000031340. 68494.34

[33] Heemskerk JW, Mattheij NJ, Cosemans JM. Platelet-based coagulation: different populations, different functions. Journal of Thrombosis and Haemostasis: JTH. 2013; 11: 2-16. PMid:23106920. https://doi.org/10.1111/jth. 12045

[34] Jackson SP. Arterial thrombosis-insidious, unpredictable and deadly. Nature Medicine. 2011; 17: 1423-36. PMid:22064432. https: //doi.org/10.1038/nm. 2515

[35] Cowan PJ, Roussel JC, d'Apice AJ. The vascular and coagulation issues in xenotransplantation. Current Opinion in Organ Transplantation. 2009; 14: 161-7. https://doi.org/10.1097/MOT.0b013e 3283279591

[36] Lawson JH, Platt JL. Molecular barriers to xenotransplantation. Transplantation. 1996; 62: 303-10. https://doi.org/10.1097/0000 7890-199608150-00001

[37] Bulato C, Radu C, Simioni P. Studies on coagulation incompatibilities for xenotransplantation. Methods in Molecular Biology. 2012; 885: 71-89. PMid:22565991. https ://doi .org/10.1007/978-1 -61779-845-0_6

[38] Roussel JC, Moran CJ, Salvaris EJ, et al. Pig thrombomodulin binds human thrombin but is a poor cofactor for activation of human protein $\mathrm{C}$ and TAFI. American Journal of Transplantation: official journal of the American Society of Transplantation and the American Society of Transplant Surgeons. 2008; 8: 1101-12. PMid:18444940. https://doi.org/10.1111/j.1600-6143.2008.02210.x

[39] Schulte Am Esch J, Robson SC, Knoefel WT, et al. O-linked glycosylation and functional incompatibility of porcine von Willebrand factor for human platelet GPIb receptors. Xenotransplantation. 2005; 12: 30-7. PMid:15598271. https ://doi.org/10.1111/j.1399 $-3089.2004 .00187 . \mathrm{x}$

[40] Miwa Y, Yamamoto K, Onishi A, et al. Potential value of human thrombomodulin and DAF expression for coagulation control in pigto-human xenotransplantation. Xenotransplantation. 2010; 17: 26-37. PMid:20149186. https://doi.org/10.1111/j.1399-3089. 20 $09.00555 . \mathrm{x}$

[41] Cozzi E, White DJ. The generation of transgenic pigs as potential organ donors for humans. Nature Medicine. 1995; 1: 964-6. https://doi.org/10.1038/nm0995-964

[42] McGregor CG, Ricci D, Miyagi N, et al. Human CD55 expression blocks hyperacute rejection and restricts complement activation in Gal knockout cardiac xenografts. Transplantation. 2012; 93: 686-92. PMid:22391577. https ://doi .org/10.1097/TP.0b013e31824 72850

[43] Ji H, Li X, Yue S, et al. Pig BMSCs Transfected with Human TFPI Combat Species Incompatibility and Regulate the Human TF Pathway in Vitro and in a Rodent Model. Cellular Physiology and Biochemistry: international journal of experimental cellular physiology, biochemistry, and pharmacology. 2015; 36: 233-49. PMid:25967963. https://doi.org/10.1159/000374067

[44] Ramirez P, Chavez R, Majado M, et al. Life-supporting human complement regulator decay accelerating factor transgenic pig liver xenograft maintains the metabolic function and coagulation in the 
nonhuman primate for up to 8 days. Transplantation. 2000; 70: 98998. https://doi.org/10.1097/00007890-200010150-00001

[45] Morgan BP, Berg CW, Harris CL. "Homologous restriction" in complement lysis: roles of membrane complement regulators. Xenotransplantation. 2005; 12: 258-65. PMid:15943774. https://doi.org/ $10.1111 / j .1399-3089.2005 .00237 . x$

[46] Gibbins JM. Platelet adhesion signalling and the regulation of thrombus formation. Journal of Cell Science. 2004; 117: 3415-25. PMid:15252124. https://doi.org/10.1242/jcs.01325

[47] Rivera J, Lozano ML, Navarro-Nunez L, et al. Platelet receptors and signaling in the dynamics of thrombus formation. Haematologica. 2009; 94: 700-11. PMid:19286885. https ://doi.org/10.3324/ haematol.2008.003178

[48] Coppinger JA, Cagney G, Toomey S, et al. Characterization of the proteins released from activated platelets leads to localization of novel platelet proteins in human atherosclerotic lesions. Blood. 2004; 103: 2096-104. PMid:14630798. https ://doi.org/10.1182/bl ood-2003-08-2804

[49] Siegel-Axel DI, Gawaz M. Platelets and endothelial cells. Seminars in thrombosis and hemostasis. 2007; 33: 128-35. PMid:17340460. https://doi.org/10.1055/s-2007-969025

[50] Choi I, Kim SD, Cho B, et al. Xenogeneic interaction between human CD40L and porcine CD40 activates porcine endothelial cells through NF-kappaB signaling. Molecular Immunology. 2008; 45: 575-80. PMid:17675236. https ://doi.org/10.1016/j.molimm. 2007. 06.161

[51] Ramackers W, Klose J, Tiede A, et al. Effect of TNF-alpha blockade on coagulopathy and endothelial cell activation in xenoperfused porcine kidneys. Xenotransplantation. 2015; 22: 284-94. PMid:26216261. https ://doi.org/10.1111/xen.12179

[52] Batten P, Yacoub MH, Rose ML. Effect of human cytokines (IFNgamma, TNF-alpha, IL-1 beta, IL-4) on porcine endothelial cells: induction of MHC and adhesion molecules and functional significance of these changes. Immunology. 1996; 87: 127-33. PMid:8666424.

[53] Kirkiles-Smith NC, Tereb DA, Kim RW, et al. Human TNF can induce nonspecific inflammatory and human immune-mediated microvascular injury of pig skin xenografts in immunodeficient mouse hosts. Journal of Immunology. 2000; 164: 6601-9. https://doi. org/10.4049/jimmunol.164.12.6601

[54] Gleissner CA, von Hundelshausen P, Ley K. Platelet chemokines in vascular disease. Arteriosclerosis, Thrombosis, and Vascular Biology.
2008; 28: 1920-7. PMid:18723831. https://doi.org/10.1161/ ATVBAHA . 108.169417

[55] Gear AR, Camerini D. Platelet chemokines and chemokine receptors: linking hemostasis, inflammation, and host defense. Microcirculation. 2003; 10: 335-50. https://doi.org/10.1080/mic.10.3-4.3 35.350

[56] Kubota T, Fukuya Y, Hashimoto R, et al. Possible involvement of chemokine-induced platelet activation in thrombophilic diathesis of antiphospholipid syndrome. Annals of the New York Academy of Sciences. 2009; 1173: 137-45. PMid:19758142. https://doi.or $\mathrm{g} / 10.1111 / \mathrm{j} .1749-6632.2009 .04648 . \mathrm{x}$

[57] Lentz SR, Tsiang M, Sadler JE. Regulation of thrombomodulin by tumor necrosis factor-alpha: comparison of transcriptional and posttranscriptional mechanisms. Blood. 1991; 77: 542-50. PMid:1846763.

[58] Navarro A, Frevel M, Gamero AM, et al. Thrombomodulin RNA is destabilized through its 3'-untranslated element in cells exposed to IFN-gamma. Journal of interferon \& cytokine research : the official journal of the International Society for Interferon and Cytokine Research. 2003; 23: 723-8. PMid:14769148. https ://doi.org/10 .1089/107999003772084833

[59] Cowan PJ, Robson SC, d'Apice AJ. Controlling coagulation dysregulation in xenotransplantation. Current Opinion in Organ Transplantation. 2011; 16: 214-21. PMid:21415824. https ://doi .org/10 .1097/MOT . Ob013e3283446c65

[60] Villegas-Mendez A, Montes R, Ambrose LR, et al. Proteolysis of the endothelial cell protein $\mathrm{C}$ receptor by neutrophil proteinase 3 . Journal of Thrombosis and Haemostasis: JTH. 2007; 5: 980-8. PMid:17459006. https ://doi.org/10.1111/j.1538-7836.20 $07.02480 . \mathrm{x}$

[61] Candinas D, Lesnikoski BA, Hancock WW, et al. Inhibition of platelet integrin GPIIbIIIa prolongs survival of discordant cardiac xenografts. Transplantation. 1996; 62: 1-5. https ://doi .org/10 .1097/00007890-199607150-00001

[62] Brandl U, Jockle H, Erhardt M, et al. Reduced fibrin deposition and intravascular thrombosis in hDAF transgenic pig hearts perfused with tirofiban. Transplantation. 2007; 84: 1667-76. PMid:18165780. https://doi.org/10.1097/01.tp.0000295742.45413.dc

[63] Cantu E, Balsara KR, Li B, et al. Prolonged function of macrophage, von Willebrand factor-deficient porcine pulmonary xenografts. American Journal of Transplantation: official journal of the American Society of Transplantation and the American Society of Transplant Surgeons. 2007; 7: 66-75. PMid:17109734. https ://doi .org/10 .1111/j.1600-6143.2006.01603.x 